\title{
SISA RANGKA MANUSIA DARI SITUS GUNUNG WINGKO
}

\section{Koeshardjono}

Keywords: palaeoanthropology; archaeology; human remains; skeletal; prehistory; settlement

\section{How to Cite:}

Koeshardjono. (1987). SISA RANGKA MANUSIA DARI SITUS GUNUNG

WINGKO. Berkala Arkeologi, 8(2), 47-57. https:/ / doi.org/10.30883/jba.v8i2.492

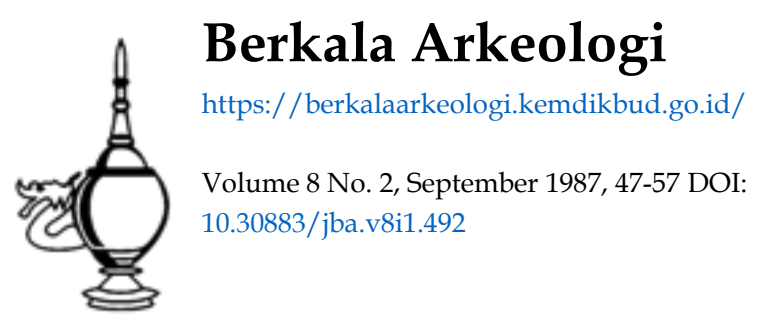




\title{
SISA RANGKA MANUSIA DARI SITUS GUNUNG WINGKO
}

\author{
Koeshardjono
}

Situs Gunung Wingko merupakan situs hunian pantai. Situs seperti ini juga ditemukan di luar Jawa, seperti di Gilimanuk (Bali), Gunung Piring (Lombok) dan Melolo (Sumba) (Nitihaminoto, 1982). Pendukung kebudayaan Gunung Wingko tinggal tidak jauh dari pantai, yaitu di sekitar bukit pasir yang terletak dekat dengan sungai.

Peninggalan prasejarah, khususnya rangka manusia, masih sangat langka. Demikian pula di Indonesia, apalagi dari periode post-Plestosen (Boedhisampoerno dan Koeshardjono, 1983). Beberapa rangka dari Indonesia yang dapat ditemukan antara lain berasal dari situs Anyar Lor (Jacob. 1964), Puger dan Sampung (Snell, 1948). Akhir-akhir ini ditemukan rangka manusia dari Bancar dan Surabaya (Sukadana, 1970, 1976), maupun Caruban (Boedhisampoerno, 1981).

Pada dasarnya, ras pokok dari periode post-Plestosen di Indonesia berkisar antara ras Austromelanesid dan Mongolid (Snell, 1948; Jacob, 1967). Dapat dikatakan bahwa di Indonesia bagian barat dan utara, terdapat unsur-unsur Mongolid yang nyata dan dominan jika manusianya berasal dari masa yang lebih muda. Di lain pihak, unsur-unsur Austromelanesid kelihatan dominan jika manusianya berasal dari masa yang lebih tua. Percampuran ras tentu saja telah terjadi, akan tetapi dengan kadar percampuran yang berbeda, sesuai dengan ruang dan waktunya.

Pada tahun 1972 dan 1973 telah dilakukan ekskavasi di Gunung Wingko, yang terletak di wilayah pantai selatan Kabupaten Bantul, DIY. Pelaksanaannya dilakukan oleh tim penelitian dari 
Proyek Penelitian Purbakala Yogyakarta, yang kemudian temuantemuan yang berasal dari sisa rangka manusia maupun hewan dikirimkan ke Laboratorium Bicanthropologi dan Paleoanthropologi Fakultas Kedokteran Universitas Gadjah Mada. Sisa rangka manusia tersebut keadaannya sudah fragmenter dan tidak lengkap. Fragmen tengkorak meliputi tulang-tulang frontale, parietale, temporale dan occiptale. Di samping itu terdapat juga fragmen rahang bawah dan beberapa fragmen gigi berbagai jenis sejumlah 16 buah, serta tulang-tulang post-kranial dari tulang anggota atas dan bawah. Gigi-gigi hewan yang ditemukan berasal dari hewan anjing, sapi, dan ikan.

Setelah bahan dibersihkan, ditempuh cara kerja melalui pemilahan jenis tulangnya. Kemudian dilakukan penelitian anthroposkopik dan anthropometrik, perbandingan, identifikasi ras, jenis kelamin dan umur, serta perhitungan-perhitungan.

\section{II}

Berdasarkan analisis terhadap sisa rangka tersebut, dapat diuraikan hasil-hasil seperti tersebut di bawah ini.

1. Dari ekskavasi tahun 1972 , dapat diidentifikasi fragmen tulang frontale, parietale, temporale, occipitale, serta fragmen rahang bawah dan beberapa fragmen gigi. Juga terdapat fragmen tulang femur dan tibia, fragmen tulang dan gigi sapi, anjing dan fragmen gigi ikan.

2. Hasil ekskavasi tahun 1973 menunjukkan fragmen tulang perietale dan beberapa fragmen gigi, fragmen tulang femur, tibia, fibula, patella, talus, metatarsal, dan phalanx.

Hasil pengukuran sisa rangka hasil ekskavasi tahun 1972 menunjukkan jenis tulang : 
a. Cranial;

- panjang maksimum

- lebar maksimum

- tinggi porion-bregma

- lebar frontal maksimum

- lebar frontal minimum

- jarak bregma-glabella

- tebal os parietale

- Cranical index

- Cranical Length-hight index

- Cranical Breadth-hight index

- Fronto-parietal index

- Fronto minimum-maximum index :

- Cranical capacity

b. Mandibula;

- panjang total mandibula

- lebar bicondylus

- lebar bigonial

- tinggi condylus

- lebar ramus mandibulae

- tinggi corpus mandibuláe

- tebal corpus mandibulae

- Mandibula index

- Fronto-goniac index

- Gonio-condylarindex

- Ramus index

- sudut mandibula

- sudut symphyseal/mental

c. Femur;

- lingkaran diaphyse

- diameter sagital

- diameter transversal

- Pilastric index

- tinggi tubuh (dasar femur)
: $\quad 18,5 \mathrm{~cm}$

: $\quad 14,6 \mathrm{~cm}$

: $\quad 11,7 \mathrm{~cm}$

: $\quad 11,4 \mathrm{~cm}$

: $\quad 9,0 \mathrm{~cm}$

: $\quad 9,2 \mathrm{~cm}$

: $\quad 0,7 \mathrm{~cm}$

: 78,9 (mesocran)

63,2 (hypsicrane)

80,1 (metriocrane)

61,6 (sthenometopia)

78,9 (divergent)

1526,7 cc.
$9,5 \mathrm{~cm}$

$11,6 \mathrm{~cm}$

$9,9 \mathrm{~cm}$

$6,3 \mathrm{~cm}$

$3,7 \mathrm{~cm}$

$2,8 \mathrm{~cm}$

$1,2 \mathrm{~cm}$

81,8 (brachygnathus)

85,3

85,3

51,6

: $122^{\circ}$

: $80^{\circ}$ $\begin{array}{cc}: & 9,4 \mathrm{~cm} \\ : & 2,8 \mathrm{~cm} \\ : & 2,6 \mathrm{~cm} \\ : & 107,7 \\ : & 170,16 \mathrm{~cm}\end{array}$ 
Pengukuran sisa rangka hasil ekskavasi tahun 1974 diperoleh:

- diameter antero-posterial tibia : $2,8 \mathrm{~cm}$.

TABEL 1. Ukuran gigi Gunung Wingko (mm).

\begin{tabular}{c|c|c|c}
\hline Gigi & Diameter mesiodistal & Diameter buccolingual & Tinggi mahkota \\
\hline $\mathrm{M}^{2}$ & 10,3 & 10,7 & 6,4 \\
& 10,0 & 10,5 & 6,0 \\
$\mathrm{M}^{1}$ & 11,0 & 11,4 & 6,3 \\
& 11,2 & 11,6 & 7,1 \\
$\mathrm{P} 1$ & 7,4 & 9,5 & 5,4 \\
$\mathrm{C}^{\prime}$ & 8,1 & 7,5 & 8,3 \\
$\mathrm{P} 1$ & 7,2 & 7,5 & 5,4 \\
$\mathrm{P} 2$ & 7,7 & 8,3 & 6,2 \\
& 7,8 & 8,5 & 6,1 \\
$\mathrm{M} 1$ & 12,2 & 11,7 & 5,6 \\
& 11,6 & 10,7 & 5,5 \\
& 12,3 & 11,5 & 6,7 \\
$\mathrm{M} 2$ & 11,7 & 10,9 & 6,2 \\
& 11,6 & 10,2 & 5,7 \\
& 11,5 & 10,3 & 7,1 \\
\hline
\end{tabular}

Shoveling positif terlihat jelas pada gigi taring atas, juga terdapat mutilasi berupa pangur pada bidang occlusal rata.

TABEL 2. Keausan gigi Gunung Wingko

\begin{tabular}{c|c|c|c}
\hline Gigi & Broca I & Broca II & Broca III \\
\hline $\mathrm{M}^{2}$ & & 2 & \\
$\mathrm{M}^{1}$ & & 2 & \\
$\mathrm{P}^{1}$ & 1 & & \\
$\mathrm{C}^{\prime}$ & & 1 & \\
$\mathrm{P} 1$ & 1 & & \\
$\mathrm{P} 2$ & 2 & 3 & 1 \\
$\mathrm{M} 1$ & & 3 & \\
$\mathrm{M} 2$ & & 11 & 1 \\
\hline Jumlah & 4 & \\
\hline
\end{tabular}


TABEL 3. Jumlah, Mean dan Standard Deviasi gigi Gunung Wingko

\begin{tabular}{|c|c|c|c|c|}
\hline Gigi & $\begin{array}{l}\text { Mean, SD, } \\
\text { Jumlah }\end{array}$ & $\begin{array}{l}\text { Diameter } \\
\text { Mesiodistal }\end{array}$ & $\begin{array}{c}\text { Diameter } \\
\text { Buccolingual }\end{array}$ & $\begin{array}{l}\text { Tinggi } \\
\text { Mahkota }\end{array}$ \\
\hline \multirow[t]{3}{*}{$\mathbf{M}^{2}$} & Mean & 10,15 & 10,60 & 6,20 \\
\hline & SD & 0,15 & 0,10 & 0,20 \\
\hline & Jumlah & 2 & 2 & 2 \\
\hline \multirow[t]{3}{*}{$\mathrm{M}^{1}$} & Mean & 11,10 & 11,50 & 6,70 \\
\hline & $\mathrm{SD}$ & 0,10 & 0,10 & 0,40 \\
\hline & Jumlah & 2 & 2 & 2 \\
\hline \multirow[t]{3}{*}{$\mathrm{P}^{1}$} & Mean & 7,40 & 9,50 & 5,40 \\
\hline & $\mathrm{SD}$ & - & - & - \\
\hline & Jumlah & 1 & 1 & 1 \\
\hline \multirow[t]{3}{*}{$C^{\prime}$} & Mean & 8,10 & 7,50 & 8,30 \\
\hline & SD & - & - & - \\
\hline & Jumlah & 1 & 1 & 1 \\
\hline \multirow[t]{3}{*}{$\mathrm{P} 1$} & Mean & 7,20 & 7,50 & 5,40 \\
\hline & SD & - & - & - \\
\hline & Jumlah & 1 & 1 & 1 \\
\hline \multirow[t]{3}{*}{$\mathrm{P} 2$} & Mean & 7,75 & 8,40 & 6,15 \\
\hline & SD & 0,05 & 0,10 & 0,05 \\
\hline & Jumlah & 2 & 2 & 2 \\
\hline \multirow[t]{3}{*}{ M1 } & Mean & 11,95 & 11,20 & 6,00 \\
\hline & $\mathrm{SD}$ & 0,36 & 0,48 & 0,56 \\
\hline & Jumlah & 4 & 4 & 4 \\
\hline \multirow[t]{2}{*}{ M2 } & Mean & 11,30 & 10,10 & 6,40 \\
\hline & SD & $\begin{array}{l}0,44 \\
3\end{array}$ & $\begin{array}{l}0,23 \\
3\end{array}$ & $\begin{array}{l}0,70 \\
3\end{array}$ \\
\hline & 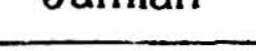 & & & \\
\hline
\end{tabular}


TABEL 4. Perbandingan beberapa macam Indeks Tengkorak deligan populasi lain.

\begin{tabular}{|c|c|c|c|c|c|c|c|c|c|c|}
\hline Macam indẹs & 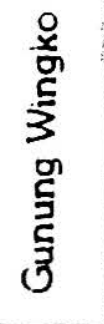 & 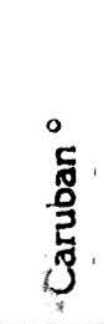 & 营! & $\frac{\frac{5}{a}}{\frac{a}{a}}$ & 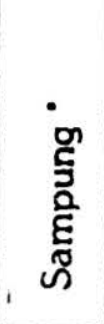 & 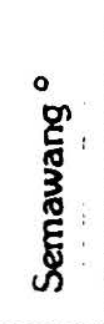 & 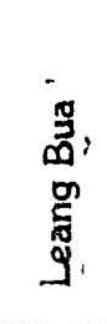 & $\frac{\circ}{\frac{0}{0}}$ & 哥 & 凅 \\
\hline $\begin{array}{l}\text { 1. Cranial index } \\
2 \text { Cranial Length. }\end{array}$ & 78.9 & 82,1 & 82,6 & 75,4 & 76,3 & 78,2 & 68,0 & 73,3 & 74,6 & 72,0 \\
\hline $\begin{array}{l}\text { height index } \\
3 \text { Cianial Breadih }\end{array}$ & 63.2 & 80,7 & 65,7 & 65,3 & 65,8 & 68,8 & 67,9 & 60.8 & 60,4 & 61,2 \\
\hline $\begin{array}{l}\text { height index } \\
\text { 4. Fronto parietal }\end{array}$ & 80,1 & 98,7 & 79,9 & 89.5 & 81.5 & 88,0 & 00.0 & 83,1 & 81,2 & 85,2 \\
\hline $\begin{array}{l}\text { index } \\
\text { 5. Gonio condylar }\end{array}$ & 61,6 & 63,8 & 64,7 & 66,1 & 65,7 & 68,4 & 61,2 & 68,5 & & 71,9 \\
\hline index & 85,3 & 80,2 & & & & & 85.9 & & & \\
\hline 6. Rumus index & 51,6 & 53,2 & & & & & 66,6 & & & \\
\hline
\end{tabular}

'Srell (1948); 'Sukadana (1970, 1976); ${ }^{\circ}$ Boedhisanpurno $(1981,1984)$.

TABEL 5. Perbandingan Robusticity, Tinggi Condylar dan Lebar iamus Mandibulae dengan beber apa populasi lain.

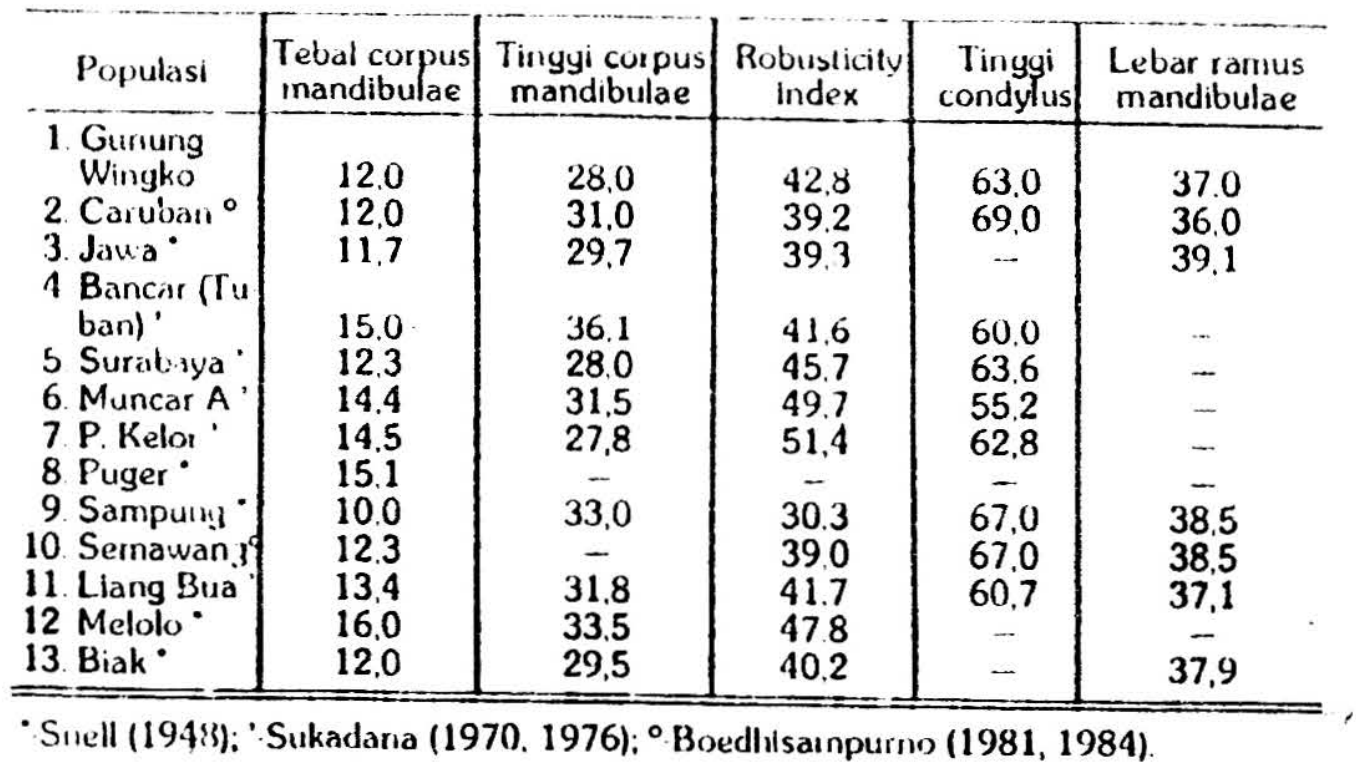


TABEL 6. Perbandingan ukuran mesiodistal dan buccolingual gigi Gunung Wingko dengan populasi lain.

\begin{tabular}{|c|c|c|c|c|c|c|c|c|}
\hline Populasi & \multicolumn{4}{|c|}{ Mesiodistal } & \multicolumn{4}{|c|}{ Buccolingual } \\
\hline Gigl at as & $M^{2}$ & $M^{1}$ & $p^{\prime}$ & $C^{\prime}$ & $\mathrm{M}^{2}$ & $\overline{M^{1}}$ & $\mathrm{Pl}$ & $C^{\prime}$ \\
\hline 1. Gunung Wingko & 10,15 & 11,1 & 7,4 & 8.1 & 10,6 & 11,5 & 9.5 & 7.5 \\
\hline 2. Caruban ${ }^{\circ}$ & 10.0 & 10.6 & 7,6 & 8,3 & 10.7 & 11,1 & 9.4 & 7,9 \\
\hline 3. Jawa • & 9.9 & 10,7 & 7,5 & 7,9 & 11,5 & 11,7 & 9.7 & 8,3 \\
\hline 4. Anjar Lor". & & -1 & - & $\therefore$ & - & $I$ & $\ldots$ & \\
\hline 5. Sangiran $\cdots$ & 10.0 & 10,7 & - & - & 11.4 & 11.5 & $\ldots$ & \\
\hline 6. Gua Kepah " & 10,4 & 10.9 & 7,4 & 8,0 & 11.9 & 11,9 & 9.8 & 88 \\
\hline 7. Sellawang ${ }^{\circ}$ & 9.2 & 10,4 & 8.2 & 7,7 & 10,4 & 10,8 & 9.4 & 8.3 \\
\hline 8. Gunung Piring ${ }^{\circ}$ & 10.1 & - & 7.7 & 8,03 & 11.6 & -. & 100 & 8.03 \\
\hline 9. Gilimanuk “• & 10,0 & 10,8 & 7.6 & 7,9 & 11.4 & 11.5 & 8.7 & 8.0 \\
\hline 10. Ulu I eang ${ }^{\circ}$ & 9.5 & 10.5 & - & & 11.7 & 11.8 & & \\
\hline 11. Leang Codong" & 10,1 & 10.7 & 7.5 & 8.0 & 11.5 & 11.8 & 9,3 & 8.3 \\
\hline 12. Llang Bua ${ }^{\circ}$ & 10,1 & 10.7 & 7.4 & 8.0 & 12.3 & 123 & 9.9 & 8.9 \\
\hline 13. Flores" & 10.0 & 10,9 & 7.5 & 8,4 & 119 & 12.1 & 10.1 & 9.1 \\
\hline 14 Melolo $^{\infty}$ & 9.8 & 10.3 & 7,5 & & 11.4 & 11,2 & 9.8 & \\
\hline 15. Aleut ${ }^{\circ}$ & 9.9 & 10.2 & 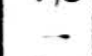 & -. & 11.3 & 11.3 & 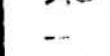 & \\
\hline 16. Australuid' & 10,9 & 11,4 & 7.8 & 8.4 & 12,8 & 10,1 & 10,3 & 9,0 \\
\hline Gigi bawah & M2 & MI & P2 & P1 & M2 & M1 & $P 2$ & P1 \\
\hline 1. Gumuny Wingko & 11,3 & 11,95 & 7.75 & 7,2 & 10.1 & 11,2 & 8.4 & 75 \\
\hline 2. Cmuban ${ }^{\circ}$ & 10.6 & 11.2 & 7.7 & 7.4 & 9.8 & 10.5 & 8.1 & 7.6 \\
\hline 3 Jawa & 10.8 & 11.4 & 7.3 & 7,3 & 10.4 & 10,9 & 8.4 & 8,1 \\
\hline 4. Arijar Lor " & 9,5 & 10.5 & - & & 10.0 & 11,0 & 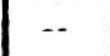 & \\
\hline 5. Sangiran $\cdots$ & 11.3 & 11.8 & - & - & 10.4 & 10,7 & - & \\
\hline 6. Gua Kepoh" " & 11,7 & 12.2 & 7.8 & 7.9 & 109 & 11.4 & 8.9 & 8.7 \\
\hline 7. Semawang ${ }^{\circ}$ & 9.9 & 10.9 & 7,3 & 7,4 & 9,0 & 9.3 & 8,1 & 8.7 \\
\hline 8. Gunung Piting ${ }^{\circ}$ & & -.. & 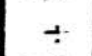 & $\ldots$ & - & 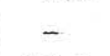 & & \\
\hline 9 Gilimanuk *. & 11.1 & 11.6 & 7,3 & 7,3 & 10,7 & 11,0 & 8,5 & 8,1 \\
\hline 10 Ulu Leang $^{\circ}$ & 10.6 & 11,7 & & & 10.1 & 10.5 & & \\
\hline 11. Leang Codong ${ }^{\circ}$ & 11,2 & 12.0 & 7.5 & 7,5 & $10, \dot{4}$ & 10.9 & 84 & 8.0 \\
\hline 12. Liang Bua ${ }^{\circ}$ & 11.6 & 12.5 & 7,7 & 7.7 & 10.6 & 11,1 & 8.6 & 8.5 \\
\hline 13 Flores" & 11,4 & 12.0 & 7.4 & 7.2 & 10.7 & 11,1 & 8,8 & 8.5 \\
\hline 14. Melolow & 11,1 & 11.7 & 7,5 & 7.7 & 10,3 & 10,7 & 8.4 & 8,4 \\
\hline 15. Aleut ${ }^{\circ}$ & \begin{tabular}{|l|}
9,9 \\
\end{tabular} & 102 & - & - & 11.3 & 11,3 & $\ldots$ & $\ldots$ \\
\hline 16 Australoid' & $12,5 \mid$ & 12,3 & 7,7 & 7.6 & 11,7 & 11,9 & 8.9 & 8.8 \\
\hline
\end{tabular}

- Mijsberg (1931) dan Moonees (1957); “ Jacob (1961); “.” Boedhihar tono (1973); " Jacob (1967); ' Gambell (1925); ${ }^{\circ}$ Beredhisampurno (1975. 1980, 1981, 1981); ${ }^{\infty}$ Snell (1948); ${ }^{\circ}$ Moorrees (1957); ${ }^{\circ}$ Boedluisampuno dan Kueshrardjono (1983) 
TABEL 7. Perbandingan Pilastric index dan Tinggi Tubuh Gunung Wingko dengan populasi lain.

\begin{tabular}{|c|c|c|}
\hline Populasi & Pilastric index & Tinggi Tubuh $(\mathrm{Cm})$ \\
\hline 1. Gunung Wingko & 107,7 & 170,16 \\
\hline 2. Gunung Piring ${ }^{\circ}$ & - & 164,9 \\
\hline 3. Caruban ${ }^{\circ}$ & 103,4 & 158,0 \\
\hline 4. Muncar $A$, & - & 165,5 \\
\hline 5. Bancar (Tuban)' & - & 173,1 \\
\hline 6. Surabaya' & - & 150,0 \\
\hline 7. Semawang ${ }^{\circ}$ & 104,3 & 157,5 \\
\hline 8. Sāmpung * & - & 170,0 \\
\hline 9. Gua Kepah * & 111.9 & 153,4 \\
\hline 10. Wadijāik * & - & 173,4 \\
\hline 11. Liang Bua' & 115,8 & 160,9 \\
\hline 12. Liang Toge * & 93,6 & 153,0 \\
\hline 13. Liang Momer $E^{*}$ & 112,0 & 169,2 \\
\hline 14. Lewoleba' & 112,2 & 161,0 \\
\hline 15. Flores * & 121,2 & - \\
\hline
\end{tabular}

-Jacob (1967); '-Sukadana (1970, 1976); ․-Boedhisampurno (1981, 1984); o'-Boedhisampurno dan Koeshardjono (1983).

\section{III}

Kondisi sisa rangka manusia Gunung Wingko memang cukup menyedihkan karena sudah rapuh dan fragmenter. Keadaan seperti ini menyulitkan untuk analisis, apalagi tanpa catatan anthroposkopis maupun anthropometris.

Sisa tengkorak menunjukkan ketebalan ubun-ubun yang berkisar seperti manusia modern lainnya. Tengkorak Gunung Wingko termasuk mesocranial (Tabel 4). Umumnya ras Mongolid mempunyai brachycranial, tetapi sebagian juga menunjukkan tengkorak mesocranial seperti halnya tengkorak Kelor (Sukadana, 1976). Di lain 
pihak, ras Austromelanesid umumnya mempunyai tengkorak dolichocranial yang tampak pada tengkorak dari Puger, Sampung, Liang Bua, Melolo dan Biak (Snell, 1948; Sukadana, 1970).

Dari beberapa indeks menunjukkan bahwa tengkorak Gunung Wingko termasuk hypsicrane/hight skull, sama dengan tengkorak Semawang dan Caruban (Boedhisampoerno, 1981; 1984) maupun tengkorak Kelor dan Liang Bua (Sukadana 1970; 1976); serta mendekati Jawa dan Sampung (Snell, 1948). Dari cranial breadthhight indeks termasuk metriocrane/medium skull, sama dengan Melolo, Sampung, Puger dan Biak.|Frontoparietal indeks Gunung Wingko menunjukkan dahi yang sempit (sthenometopia), yang menyamai Caruban, Jawa, Sampung dan Liang Bua. Keadaan seperth ini berbeda dengan dahi Kelor, Semawang dan Melolo yang berdahi sedang dan berbeda jauh dengan Puger dan Biak yang berdahi lebar. Rahang bawahnya termasuk brachygnathus (lebar dan pendek), sudut mandibulae sesuai dengan ras Mongoloid pada umumnya $\left(122^{\circ}\right)$.

Tabel 5 menunjukkan tebal corpus mandibulae Gunung Wingko sama dengan Semawang, Caruban (Boedhisampoerno, 1981; 1984), Jawa, Biak (Snell, 1948) dan Surabaya (Sukadana, 1976). Sedangkan tinggi corpus mandibulaenya menunjukkan kesamaan dengan Surabaya dan Kelor (Sukadana, 1976). Robusticity index menunjukkan bahwa Gunung Wingko dekat dengan Bancar dan Liang Bua (Sukadana, 1970). Foramen mentale terletak di bawah P2 seperti Semawang dan Caruban (Boedhisampoerno, 1981; 1984).

Dari perhitungan terlihat bahwa kapasitas kranialnya sudah sesuai dengan Mongolid pada umumnya, yakni 1526,7 cc.

Tabel 7 menunjukkan Pilastric index menunjukkan femur Gunung Wingko mendekati Semawang dan Caruban, Muncar A, Surabaya, Semawang, Gua Kepah, Liang Bua, Liang Toge, Lewoleba dan Gunung Piring (Boedhisampoerno dan Koeshardjono, 1983), dan berada di bawah Bancar dan Wadjak. Tinggi tersebut hampir sama atau mendekati tinggi rangka Liang Momer $(169,2 \mathrm{~cm})$ dan 
Sampung $(170,0 \mathrm{~cm})$. Manusia Indonesia sekarang bervariasi antara $135-180 \mathrm{~cm}$.

Dari ukuran-ukuran gigi yang didapat, terlihat bahwa gigi molar atas Gunung Wingko (lihat Tabel 6) dalam ukuran mesiodistal lebih kecil dari Australoid. Molar tersebut lebih besar dari Caruban, Jawa, Sangiran, Semawang, Ulu Leang, Melolo dan Aleut, dan sebanding dengan Gua Kepah, Gunung Piring, Gilimanuk, Leang Codong, Liang Bua dan Flores. Dalam ukuran buccolingual, Gunung Wingko lebih kecil dari Gua Kepah, Ulu Leang, Leang Codong, Liang Bua, Flores dan Australoid $\mathrm{M}^{1}$ Gunung Wingko lebih besar dari Australoid, dan sebanding dengan Caruban, Semawang, Sangiran, dan Gilimanuk.

Molar bawah ukuran mesiodistal Gunung Wingko lebih kecil dari Gua Kepah, Liang Bua, Flores dan Australoid. Ukuran tersebut menyamai ukuran molar Sangiran dan sebanding cengan Gilimanuk dan Leang Codong. Dalam ukuran buccolingual, Gunung Wingko lebih kecil dari Gua Kepah, Aleut dan Australoid.

Untuk gigi premolar dalam ukuran mesiodistal, Gunung Wingko lebih kecil dari Gua Kepah, Flores, Melolo dan Australoid; tetapi sama dengan Jawa dan Gilimanuk. Ukuran buccolingual juga lebih kecil dari Gua Kepah, Flores, Melolo dan Australoid; menyamai Caruban dan Semawang, serta sebanding dengan Gilimanuk.

Gigi-gigi depan Gunung Wingko sangat fragmenter. Hanya pada gigi taring atas Gunung Wingko secara keseluruhan lebih kecil dari Flores dan Australoid, tetapi sama dengan Caruban. Pada gigi taring tersebut tampak adanya bentuk "shovel" yang menjadi ciri ras Mongolid.

Secara umum dimensi giginya lebih dekat atau menyamai populasi yang berunsur Mongolid seperti populasi Gilimanuk, Jawa, dan Leang Codong.

Dari sudut kultural ditemukan adanya mutilasi yang berupa pangur pada gigi taring dengan bentuk pada bidang okklusal rata. 
Bentuk ini biasanya terdapat pada ras Mongolid. Sisa-sisa tulang hewan dari jenis sapi, anjing, dan ikan, serta sisa-sisa gerabah yang ditemukan, diduga sebagai bekal kubur. Situs Gunung Wingko merupakan situs kubur dan sekaligus situs hunian, dengan orientasi rangka ke arah timur-barat. Sistem penguburan menunjukkan sistem penguburan primer dan sekunder (Nitihaminoto, 1982). Rangka Gunung Wingko ini merupakan sisa manusia modern, yang terdiri atas 2 individu laki-laki dewasa, dengan affinitas Mongolid dan berasal dari masa perundagian. Secara anthropologis, rangka ini menunjukkan populasi yang lebih muda dibandingkan dengan populasi Gilimanuk (Bali) dan diduga semasa dengan populasi Gunung Piring (Lombok Selatan).

\section{KEPUSTAKAAN .}

Boedhisampurno, S. 1981 Sisa kerangka manusia dari Banjar Semawang, Bali. Peringatan Hari Ulang Tahun X PA.A.I, Yogyakarta.

Boedhisampurno, S. 1984. Kerangka manusia dari Caruban, Lasem Jawa Tengah. Rapat Evaluasi Hasil Penelitian A.rkeologi II, Cisarua .

Boedhisampurno, S. \& Koeshardjono 1983. Sisa kerangka manusia dari Gunung Piring, Lombok Selatan Pertemuan IImiah A.rkeologi III, Ciloto.

Jacob, T. 1967 Some Problems Pertaining to the Racial History of the Indonesia Region. Utrecht.

Nitihaminoto, G. 1982. Penelitian gerabah berhias pantai selatan Jawa Tengah Jawa Timur. Rapat Evaluasi Hasil Penelitian A.rkeologi I, Cisarua.

Snell, C. A. R. D. 1948. Human skulls from the urn-field of Melolo, East Sumba. A.cta Neerl, Morphol, Norm, et Pathol. 6 (3): 1-20.

Sukadana, A. A. 1970. Persamaan mutilasi dentisi pada kerangkakerangka prasejarah dari Liang Bua, Lewoleba dan Melolo serta beberapa catatan anthropologi mengenai penemuan-penemuan itu. Majalah Kedokteran Gigi Surabaya. 3 (2): 13-31. 